\title{
Research on a Miniature Multiparameter Water Quality Sensor Chip and a System with a Temperature Compensation Function
}

\author{
Xin Wang, ${ }^{1}$ Lining Sun, ${ }^{1,2}$ and Yunbo Shi $\mathbb{D}^{1}$ \\ ${ }^{1}$ The Higher Educational Key Laboratory for Measuring \& Control Technology and Instrumentations of Heilongjiang Province, \\ School of Measurement-Control Tech \& Communications Engineering, Harbin University of Science and Technology, \\ Harbin 150080, China \\ ${ }^{2}$ Institute Robotics and Microsystem Research Center, School of Mechanical and Electrical Engineering, Soochow University, \\ Suzhou 215301, China \\ Correspondence should be addressed to Yunbo Shi; shiyunbo@hrbust.edu.cn
}

Received 18 April 2020; Accepted 20 October 2020; Published 18 November 2020

Academic Editor: Vincenzo Marletta

Copyright (c) 2020 Xin Wang et al. This is an open access article distributed under the Creative Commons Attribution License, which permits unrestricted use, distribution, and reproduction in any medium, provided the original work is properly cited.

\begin{abstract}
This paper presents a multiparameter water quality sensor chip with temperature compensation. The sensor chip was manufactured using microelectromechanical system (MEMS) technology. The surface of the chip integrated $\mathrm{pH}$, dissolved oxygen (DO), ammonia nitrogen, and temperature sensors. To compensate for the solution temperature, the chip was also designed with a sandwich, plate-type serpentine Pt resistance heater. The experimental results showed that the $\mathrm{pH}$ sensor had a high sensitivity of $0.288 \mathrm{~mA} / \mathrm{pH}$ with good linearity $\left(R^{2}=0.9998\right)$, the sensitivity of the temperature sensor was $0.949 \Omega /{ }^{\circ} \mathrm{C}$, the sensitivity of the ammonia nitrogen sensor was $0.1139 \mathrm{~mA} / \mathrm{ppm}$, the sensitivity of the dissolved oxygen (DO) sensor was $2.22 \mu \mathrm{A} / \mathrm{ppm}$, and the sensitivity of the temperature changes with respect to the heater power was $0.3126^{\circ} \mathrm{C} / \mathrm{mW}$. Compared with a single water quality parameter sensor, the as-prepared sensor chip could simultaneously detect multiple parameters of a water sample and had a good temperature compensation effect. Moreover, the sensor chip was small in size, rugged, and highly accurate.
\end{abstract}

\section{Introduction}

Water is closely related to human life and is an important factor affecting human health. However, with the rapid development of industry and agriculture, water pollution has become increasingly serious. As water sources continue to deteriorate, the number of water-related diseases increases every year. Therefore, it is of great significance to develop a miniature sensor that can simultaneously detect multiple water quality parameters [1].

The $\mathrm{pH}$ is a critical evaluation parameter of aqueous solutions, which affects the solution properties and chemical reaction rate [2]. The World Health Organization recommends that, for residents, the $\mathrm{pH}$ of drinking water be maintained between 6.5 and 8.5 [3]. If the $\mathrm{pH}$ of drinking water exceeds the specified range, a few problems may arise. For example, if the $\mathrm{pH}$ is extremely low, water pipelines will corrode. If the $\mathrm{pH}$ value is extremely high, calcium and magnesium ions in the water will precipitate and form scale [4]. Traditional glass $\mathrm{pH}$ electrodes have the advantages of good stability, an ideal Nernst slope, good reproducibility, and long life. However, glass electrodes also have some disadvantages, such as being bulky and fragile. To overcome these shortcomings, several scientific research teams have conducted research and developed new $\mathrm{pH}$ sensors, for example, fiber-optic $\mathrm{pH}$ sensors [5] and ion-selective field-effect transistor (ISFET) $\mathrm{pH}$ sensors [6], which have received attention in recent years. Based on the characteristics of mechanical stability, potential metal oxide $\mathrm{pH}$ sensors have been extensively studied, such as $\mathrm{Ta}_{2} \mathrm{O}_{5}$ [7], $\mathrm{WO}_{3}$ [8], $\mathrm{TiO}_{2}$ [9], and $\mathrm{CuO}[10]$. In recent years, $\mathrm{pH}$ sensors consisting of a conductive polyaniline (PANI) polymer have also been reported. In particular, PANI most often exists in the form of an intermediate oxidation state (emeraldine base (EB)). Through a reduction reaction, PANI can be converted from an intermediate state to a full benzene structure (leucoemeraldine base 


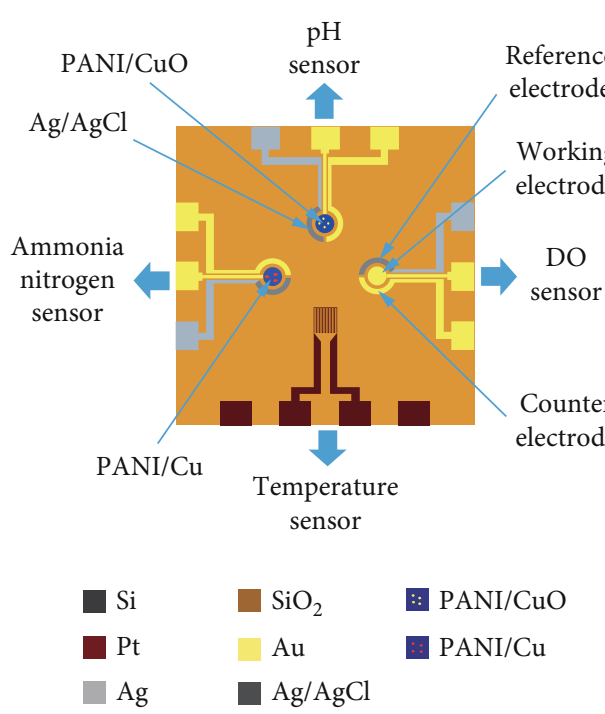

(a)

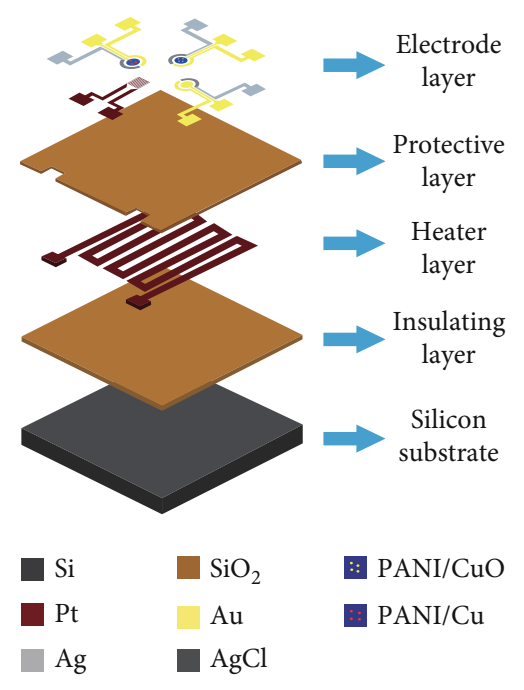

(b)

Figure 1: (a) Each component of the sensor surface. (b) The schematic diagram of each sensor layer.

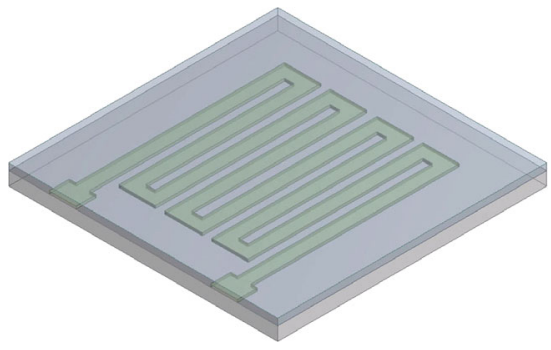

(a) First heater structure

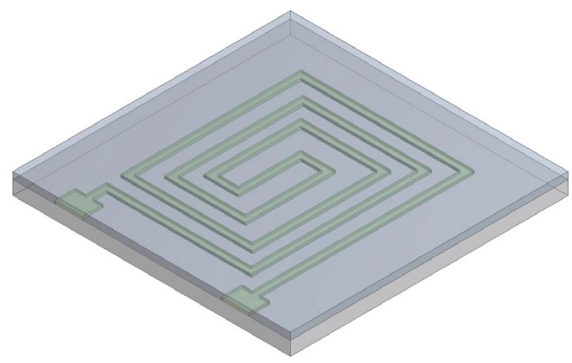

(c) Third heater structure

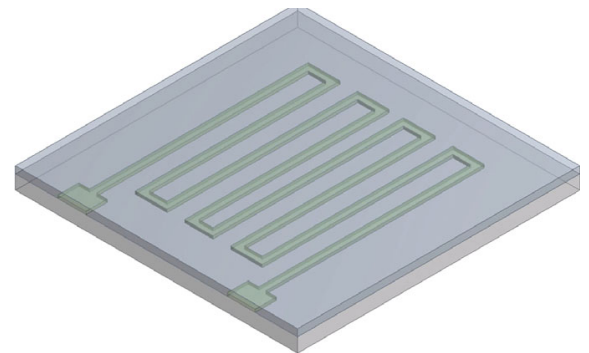

(b) Second heater structure

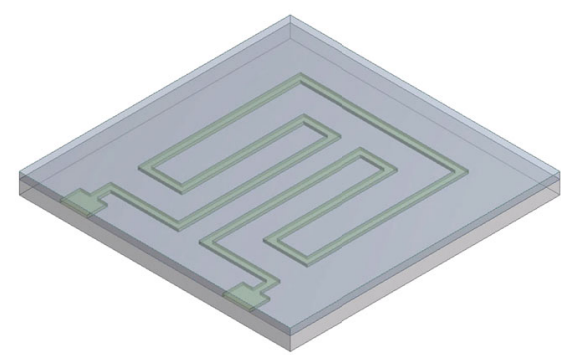

(d) Fourth heater structure

FIgURE 2: Four heating electrode structures.

(LEB)). In contrast, through an oxidation reaction, PANI can also be converted from an intermediate state to a full quinone structure (pernigraniline base). As a conductive polymer, the conductivity and optical properties of PANI vary with $\mathrm{pH}$. Therefore, based on these characteristics, PANI can be used to manufacture electrical and optical $\mathrm{pH}$ sensors [11].

Ammonia nitrogen $\left(\mathrm{NH}_{3}-\mathrm{N}\right)$ is also an important water quality parameter. Ammonia nitrogen $\left(\mathrm{NH}_{3}-\mathrm{N}\right)$ includes ammonium ions $\left(\mathrm{NH}_{4}^{+}\right)$and free ammonia $\left(\mathrm{NH}_{3}\right)$ [12]. Such pollutants often appear in liquid organic waste such as sewage and manure [13]. Excessive ammonia nitrogen can cause eutrophication of the water environment. Therefore, to prevent water pollution, it is very important to monitor the ammonia nitrogen content. The method for determining ammonia nitrogen has been studied worldwide. The traditional method for determining the $\mathrm{NH}_{3}-\mathrm{N}$ concentration is to use a colorimetric method. However, the colorimetric test process is tedious, and it easily causes secondary pollution; thus, real-time monitoring cannot be achieved. Among the various methods for ammonia nitrogen measurement, electrochemical detection exhibits a low cost, high sensitivity, good selectivity, and the possibility of real-time monitoring. 


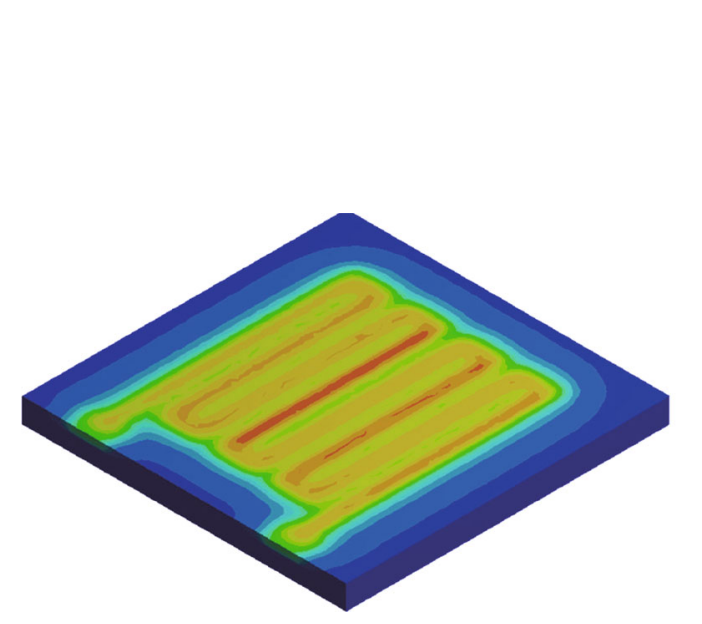

A: Steady-state thermal

Temperature

Type: temperature

Unit: ${ }^{\circ} \mathrm{C}$

Time: 1

(a) Thermal simulation of first heater

\begin{tabular}{|l}
$32.076 \mathrm{Max}$ \\
29.693 \\
27.31 \\
24.927 \\
22.543 \\
20.16 \\
17.777 \\
15.394 \\
13.01 \\
10.627 \\
8.244 \\
5.8608 \\
3.4776 \\
1.0944 \\
$-1.2888 \mathrm{Min}$
\end{tabular}

A: Steady-state thermal

Temperature

Type: temperature

Unit: ${ }^{\circ} \mathrm{C}$

Time: 1

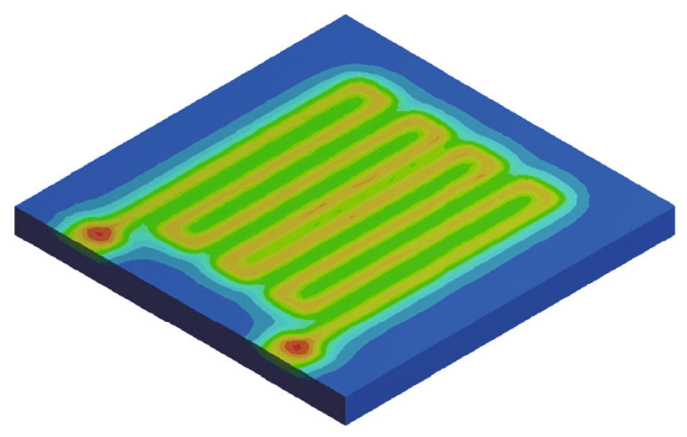

\begin{tabular}{|l}
$22.481 \mathrm{Max}$ \\
20.747 \\
19.013 \\
17.28 \\
15.546 \\
13.812 \\
12.078 \\
10.344 \\
8.6102 \\
6.8764 \\
5.1425 \\
3.4087 \\
1.6748 \\
-0.059066 \\
$-1.7929 \mathrm{Min}$
\end{tabular}

(b) Thermal simulation of second heater

A: Model, steady-state thermal Temperature

Type: temperature

Unit: ${ }^{\circ} \mathrm{C}$

Time: 1

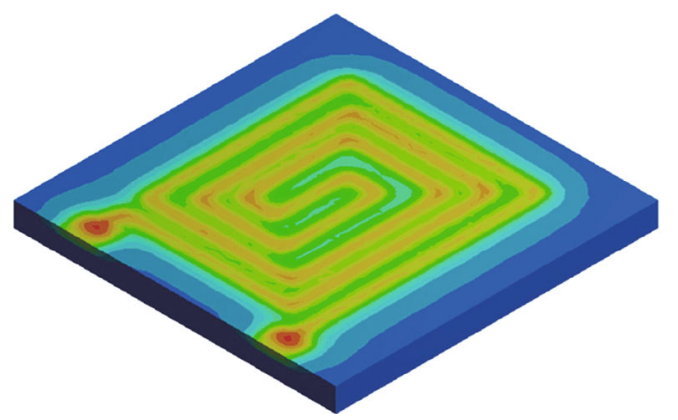

\begin{tabular}{|l}
$22.779 \mathrm{Max}$ \\
20.972 \\
19.165 \\
17.358 \\
15.551 \\
13.744 \\
11.937 \\
10.13 \\
8.3232 \\
6.5163 \\
4.7094 \\
2.9025 \\
1.0955 \\
-0.71138 \\
$-2.5183 \mathrm{Min}$
\end{tabular}

(c) Thermal simulation of third heater

Figure 3: Continued. 


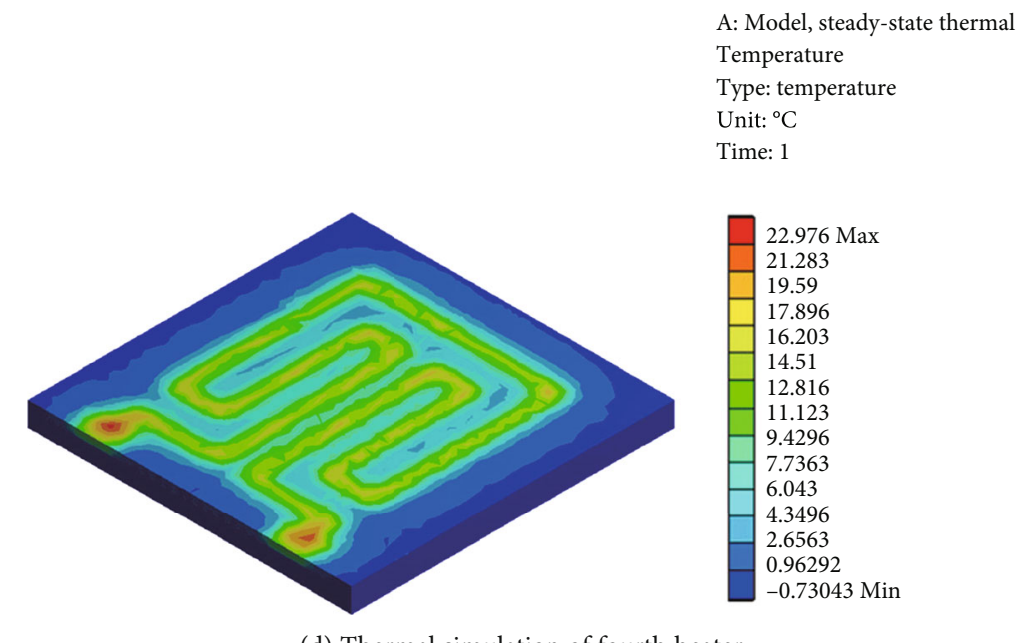

(d) Thermal simulation of fourth heater

Figure 3: Thermal simulation results of the four heating electrodes.

Therefore, various ammonium ion-selective electrodes have been developed [14]. However, due to the inherent sensing characteristics of ion-selective electrodes, the potential sensor has a low response at low target concentrations and is susceptible to interference from other ions [15]. To overcome the shortcomings of the potentiometric method, many laboratory models of amperometric ammonium ion sensors have been developed [16]. Compared with traditional colorimetric and potentiometry methods, amperometric sensors generally have higher sensitivity and lower detection limits while also being easy to implement in real-time monitoring.

Dissolved oxygen is also an important water pollution indicator. Dissolved oxygen is to molecular oxygen dissolved in water, which is denoted by DO. The concentration of DO is the number of milligrams of oxygen per liter of water, expressed in $\mathrm{mg} / \mathrm{L}$ or $\mathrm{ppm}$. Normally, the $\mathrm{DO}$ in water is close to saturation. When the oxygen in the water is consumed by organic or reducing substances, the DO concentration in the water will decrease. When the DO concentration is lower than a certain level $(<4 \mathrm{mg} / \mathrm{L})$, anaerobic bacteria in the water can multiply and give the water an odor. Therefore, the detection of DO is a necessary condition for judging the quality of water. The traditional detection method is an iodometric method. The iodometric method is an internationally recognized reference method for measuring DO in water [17]. Although the iodometric method is accurate, it requires chemical reagents. Furthermore, the steps are time consuming, and the system is bulky. Therefore, real-time monitoring is not possible $[18,19]$. Electrochemical measurements are a commonly used method and include potentiometric methods [20, 21] and amperometric methods [22]. The electrochemical measurement method has the advantages of a simple operation and a fast and efficient response, which are convenient for real-time monitoring. Therefore, it has great research value.

On the other hand, water temperature is also an important factor that affects the $\mathrm{pH}, \mathrm{DO}$ concentration, and ammonia nitrogen concentration [23-26]. To measure each parameter accurately, the solution temperature needs to be accounted for. At present, there are many studies on microscale temperature sensors $[27,28]$. The most commonly used thermistors are metal [27], polymer [28], etc. However, to integrate a temperature sensor with other water quality parameter sensors on the same silicon chip, thus, manufacturing an integrated multiparameter sensor chip has yet to be explored.

This paper proposes a multiparameter water quality sensing system that can simultaneously measure the following four parameters: $\mathrm{pH}, \mathrm{DO}$ concentration, ammonia nitrogen concentration, and temperature of the water sample. The electrode array is made of microelectromechanical system (MEMS) technology and includes three three-electrode arrays and a resistive temperature sensor. $\mathrm{PANI} / \mathrm{CuO}$ is used as the $\mathrm{pH}$-sensitive material and the ammonia nitrogensensitive material. High-purity Pt resistance sensors are used for the temperature sensor. Considering the influence of temperature on various parameters, an integrated serpentine Pt resistance heater is used to compensate for temperature. Experimental results demonstrate that the chip exhibits good sensing performance. The chip is small and structurally stable; therefore, it is suitable for mass production as well as for use in remote and distributed measurements.

\section{Materials and Methods}

2.1. Reagents and Instruments. The reagents used in the experiment were of analytical grade. Reagents were purchased from Sinopharm Group Beijing Chemical Reagent Company. Deionized water was used for dilution and cleaning. Ethanol, aniline, oxalic acid, ammonium persulfate (APS), copper chloride $\left(\mathrm{CuCl}_{2}\right)$, nanocopper powder, and ammonia $\left(\mathrm{NH}_{3} \bullet \mathrm{H}_{2} \mathrm{O}\right)$ were used to prepare polymers, such as PANI, PANI/CuO, and PANI/Cu. Acetic acid (HOAc), phosphoric acid $\left(\mathrm{H}_{3} \mathrm{PO}_{4}\right)$, and $\mathrm{NaOH}$ were used to prepare a $\mathrm{pH}$ buffer solution. Sodium sulfite $\left(\mathrm{Na}_{2} \mathrm{SO}_{3}\right)$ particles and potassium chloride $(\mathrm{KCl})$ were used to prepare a $\mathrm{DO}$ 


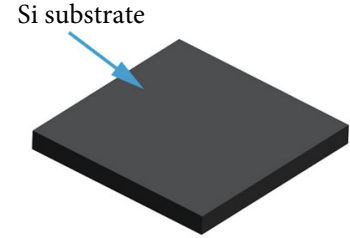

(a)

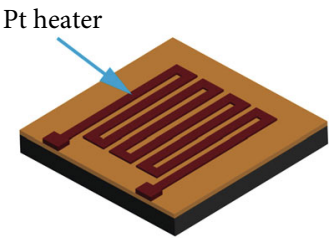

(c)

Working electrode (Au)

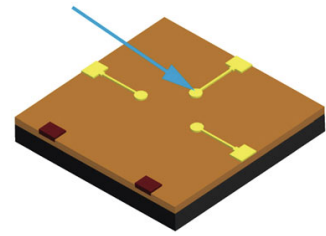

(e)

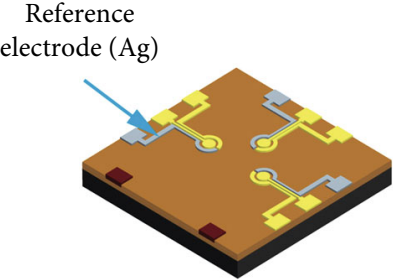

(g)

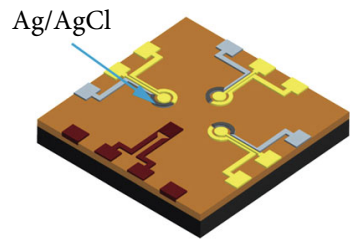

(i)

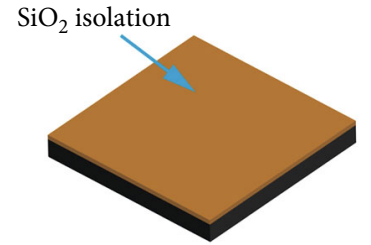

(b)

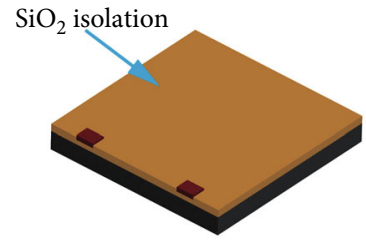

(d)

Counter electrode (Au)

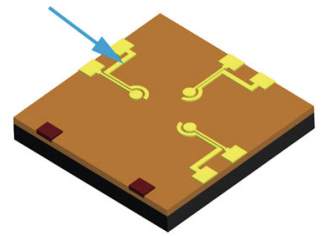

(f)

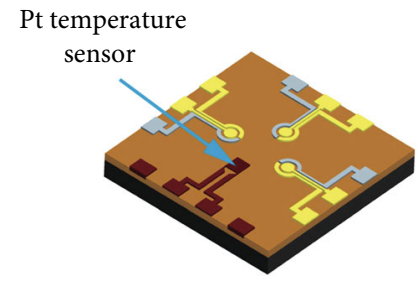

(h)

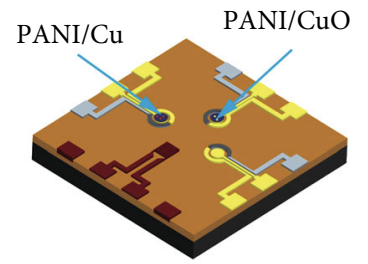

(j)

FIGURE 4: Fabrication process of the integrated sensors.

measurement solution. Ammonium chloride $\left(\mathrm{NH}_{4} \mathrm{Cl}\right)$ and potassium chloride were used to prepare an ammonia nitrogen measurement solution. Silver (Ag) powder, silver chloride $(\mathrm{AgCl})$ powder, and binder (mixture of polyvinyl butyral, ethyl cellulose, ethyl acetate, and terpineol) were used to prepare silver/silver chloride $(\mathrm{Ag} / \mathrm{AgCl})$ paste.

The instruments used in the experiment are as follows: an electronic balance (Sartorius, Germany), an ultrapure water machine (Beijing Yingan Meicheng Scientific Instrument Co., Ltd.), a laboratory-developed potentiostat, a data acquisition system (PCI-1716/1716L, Advantech, China), a signal generator (DG1032, RIGOL, China), a peristaltic pump (BT100-2J, Dichuang, China), a magnetic $\mathrm{pH}$ meter (pHS-3E, Thunder magnetic, China), a thermal imaging analyzer (Fluke, PTi120, USA), beakers, and a silicone tube.
2.2. Microelectrode Array (MEA) Sensor Design. The sensor chip contains three three-electrode arrays (ammonia nitrogen sensor, $\mathrm{pH}$ sensor, and $\mathrm{DO}$ sensor) and a Pt resistance temperature sensor (Figure 1(a)). The three electrodes of the electrode array include a working electrode, a counter electrode $(\mathrm{Au})$, and a reference electrode $(\mathrm{Ag} / \mathrm{AgCl})$ [29, 30]. The working electrodes of the three sensors are modified with different sensitive membranes. The working electrode of the DO sensor was unmodified and based on Au. The working electrode of the ammonia nitrogen sensor was modified using PANI/Cu [31], and the working electrode of the $\mathrm{pH}$ sensor was modified using $\mathrm{PANI} / \mathrm{CuO}[32,33]$. Considering the influence of temperature on the measurement of various parameters, a flat sandwich sensor structure with a serpentine heater was prepared (Figure 1(b)) [34, 35]. 


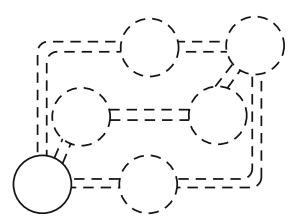

(a)

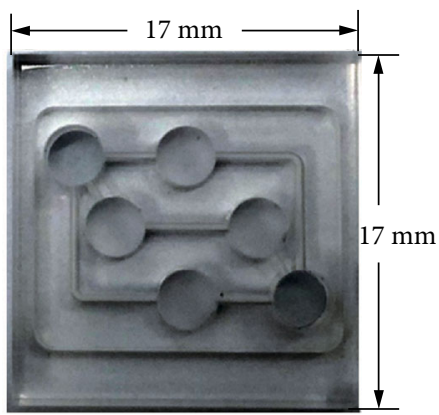

(c)

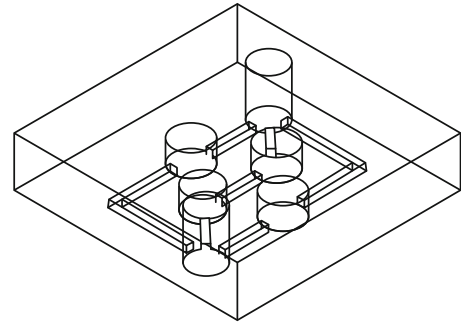

(b)

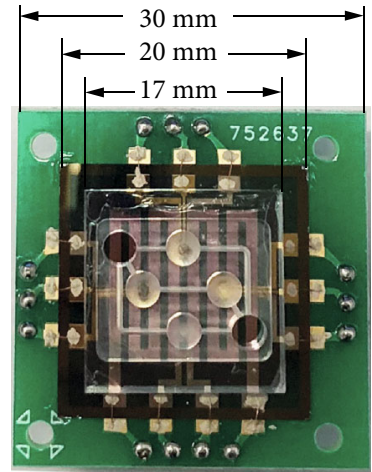

(d)

Figure 5: (a) Schematic diagram of the internal structure of the test container. (b) Schematic diagram of the three-dimensional structure of the test container. (c) Physical picture of the test container. (d) Diagram of the test container and sensor package.

When the electrochemical reaction occurs, if the solution temperature is excessively low, the power of the heating track can be adjusted according to the real-time monitored temperature, thus allowing for the surface of the electrochemical sensor to reach the ideal temperature, which ensures the stability and reliability of the various parameter measurements. To obtain an optimal heating effect, Pt was used for the heater design, and four types of heater structures were designed, as shown in Figure 2.

A finite element steady-state thermal analysis was conducted to investigate the heat transfer process of the four heater structures. Under the assumption that the ambient temperature was $0^{\circ} \mathrm{C}$, the heating generation rate was considered to be $2.13 \times 10^{10} \mathrm{~W} / \mathrm{m}^{3}$. To simplify the simulation process, the changes in the thermal conductivity due to the variation in temperature were neglected, in addition to the thermal contact resistances among the sensor layers. Figure 3 presents the thermal simulation results of the four heater types, which were subject to the same boundary conditions and heating power.

Based on the simulation results, the first type of heater structure (Figure 3(a)) demonstrated the most significant heat transfer effect, and the temperature distribution was relatively uniform. In addition, it can cover the entire electrochemical reaction region. Therefore, in this study, the first heater structure was adopted.

\subsection{Fabrication of the Sensor}

2.3.1. Fabrication of the MEA. The detailed process of the sensor fabrication is shown in Figure 4 . A single $520 \mu \mathrm{m}$ crystal silicon wafer was employed as the substrate (Figure 4(a)).
The substrate was ultrasonically cleaned with acetone and absolute ethanol. After cleaning, a 300-nm-thick $\mathrm{SiO}_{2}$ isolation layer was grown via a thermal oxidation method (Figure 4(b)). A serpentine heating electrode with a thickness of $200 \mathrm{~nm}$ was prepared by photolithography, and the target material was $\mathrm{Pt}$ (Figure 4(c)). An $\mathrm{SiO}_{2}$ insulating layer with a thickness of $500 \mathrm{~nm}$ was grown on the heating layer via a thermal oxidation method, and the insulating layer was reduced to a level between the metal layer and the insulating layer $(200 \mathrm{~nm})$. A heating electrode pad with a thickness of $500 \mathrm{~nm}$ was prepared via photolithography. Thereafter, a $\mathrm{SiO}_{2}$ layer with a thickness of $300 \mathrm{~nm}$ was grown via the oxidation method (Figure 4(d)). Using a photolithographic technique, a 200-nm-thick electrochemical sensor working electrode (Figure 4(e)) and a counter electrode (Figure 4(f)) were prepared, and the target material was Au. A reference electrode with a thickness of $200 \mathrm{~nm}$ was then prepared (Figure 4(g)), and the target material was Ag. Finally, a Pt temperature sensor with a thickness of $200 \mathrm{~nm}$ was prepared via photolithography (Figure $4(\mathrm{~h})$ ).

2.3.2. Fabrication of the Ag/AgCl Electrode. Silver powder, silver chloride powder, and binder were mixed according to a given ratio and then ground using a ball mill for $10 \mathrm{~h}$ to obtain an $\mathrm{Ag} / \mathrm{AgCl}$ slurry. The obtained slurry was coated on the Ag electrodes of the three three-electrode arrays. Then, the slurry was cured and dried at $100^{\circ} \mathrm{C}$ for $1 \mathrm{~h}$, which completed the preparation of the $\mathrm{Ag} / \mathrm{AgCl}$ electrodes (Figure 4(i)).

2.3.3. Fabrication of the PANI/Cu Electrode. PANI/Cu was prepared using a slight modification of a method reported 


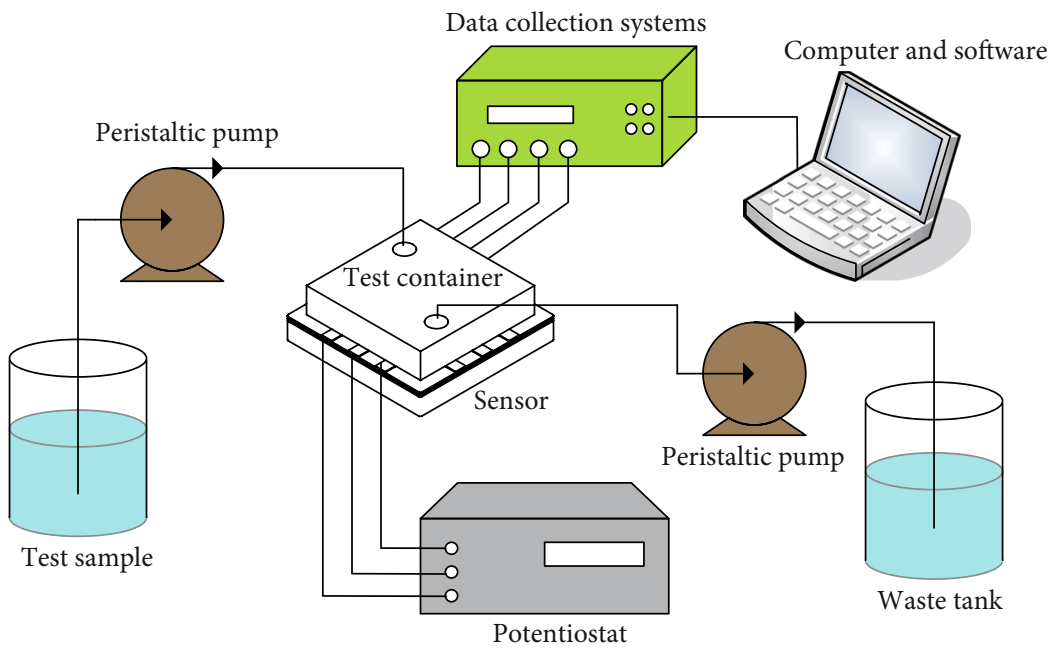

(a)
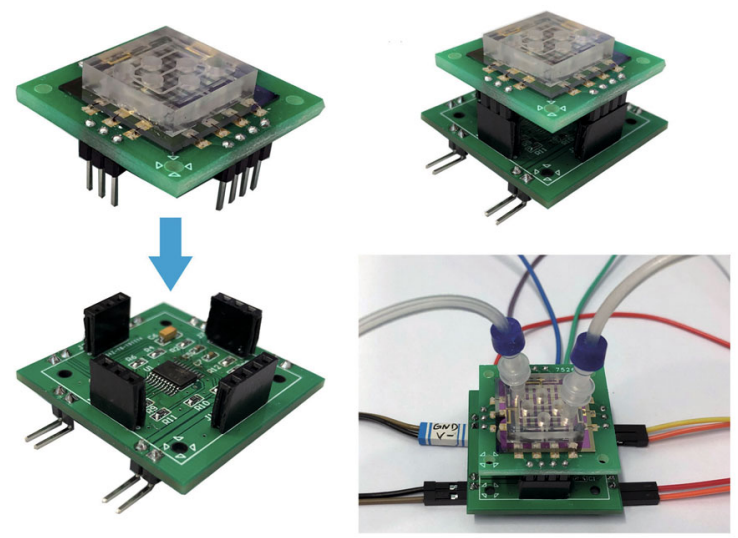

(b)

Figure 6: (a) Schematic diagram of the experimental device. (b) Test circuit.

in the literature [36]. In particular, $11.4 \mathrm{~g}$ of APS was weighed and dissolved in $25 \mathrm{~mL}$ of water for later use. Thereafter, $100 \mathrm{~mL}$ of a $0.5 \mathrm{M}$ oxalic acid solution was prepared. Next, $0.265 \mathrm{~g}$ of nanocopper was ultrasonically dispersed in $100 \mathrm{~mL}$ of $0.5 \mathrm{M}$ oxalic acid and sonicated for $30 \mathrm{~min}$. Then, $2.5 \mathrm{~mL}$ of aniline solution was prepared. The prepared APS, aniline, and oxalic acid solutions were mixed and stirred at room temperature for $6 \mathrm{~h}$. A dark green suspension was obtained and then suction filtered. The PANI/Cu precipitate was collected on filter paper after suction filtration and then washed using deionized water and absolute ethanol. After washing, the PANI/Cu was placed in a vacuum oven and dried at $65^{\circ} \mathrm{C}$ for $24 \mathrm{~h}$. The obtained PANI material was ground using a ball mill for $1 \mathrm{~h}$ to obtain a $\mathrm{PANI} / \mathrm{Cu}$ powder. $\mathrm{PANI} / \mathrm{Cu}$ powder and binder were mixed at a specific ratio, and the mixed material was evenly coated on the ammonia nitrogen working electrode. Finally, it was placed in a vacuum oven and dried at $80^{\circ} \mathrm{C}$ for $6 \mathrm{~h}$ (Figure $4(\mathrm{j})$ ).

2.3.4. Fabrication of the PANI/CuO Electrode. Nano-CuO was mixed with APS solution, oxalic acid solution, and aniline solution, followed by the preparation of a $\mathrm{PANI} / \mathrm{CuO}$ powder in accordance with the PANI/Cu synthesis method.
$\mathrm{PANI} / \mathrm{CuO}$ powder and binder were mixed in a specific ratio, and the mixed material was evenly coated on the $\mathrm{pH}$ sensor working electrode. Finally, it was placed in a vacuum oven and dried at $80^{\circ} \mathrm{C}$ for $6 \mathrm{~h}$ (Figure $4(\mathrm{j})$ ).

\subsection{Experimental Setup and Measurement}

2.4.1. Test Container. Combined with polymethylmethacrylate (PMMA) microfluidic technology, a microfluidic test container was prepared. The test container, which was fabricated using plexiglass processing, is shown in Figure 5(c). Figure 5(a) is a schematic diagram of the internal structure of the test container. Figure 5(b) is a three-dimensional schematic diagram of the test container. The test container was adhered to the printed circuit board (PCB) of the sensor using insulating glue. The test container and sensor package are shown in Figure 5(d).

2.4.2. Experimental Device. The schematic of the entire experimental device is shown in Figure 6(a). A peristaltic pump transferred the test liquid into the test container at a speed of $50-60 \mathrm{rpm}$. After the test chamber was filled, the temperature, $\mathrm{pH}, \mathrm{DO}$ concentration, and ammonia nitrogen 


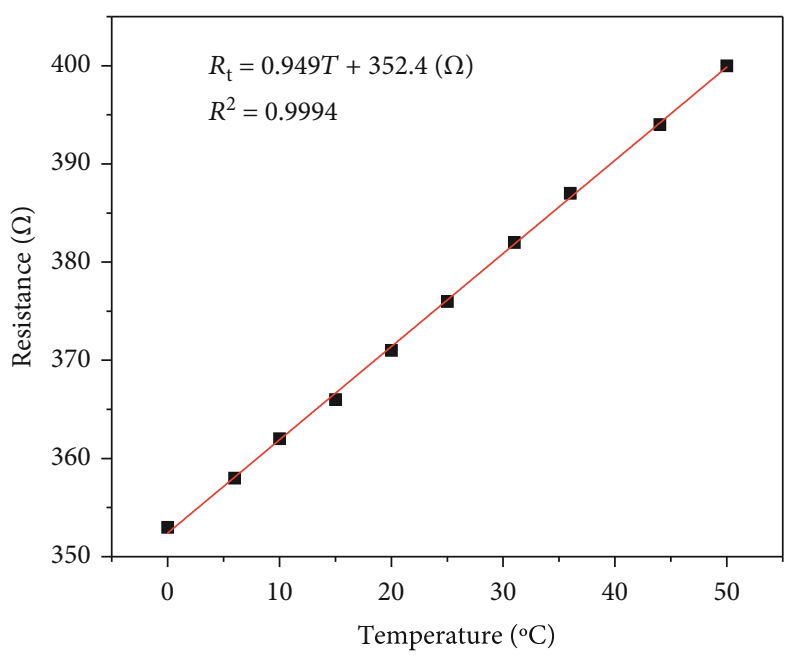

(a)

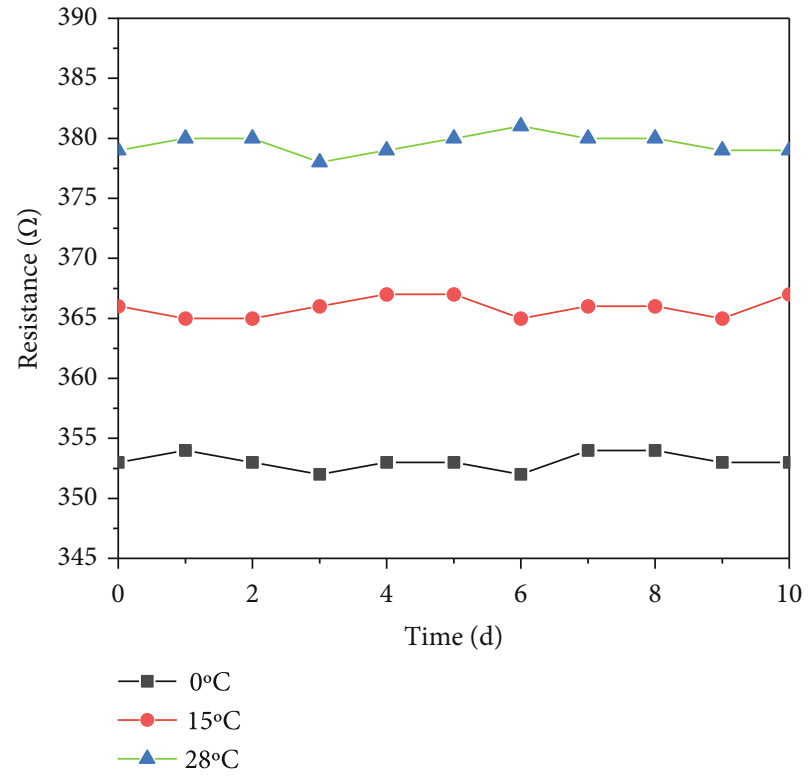

(b)

FiguRe 7: (a) Linear relationship between the Pt RTD resistance and temperature. (b) Stability test results of the temperature sensor over 10 consecutive days.

concentration of the solution were successively measured. After the test was completed, the peristaltic pump was switched on, and the liquid in the test container was discharged at the same speed. The test circuit is shown in Figure 6(b).

\section{Results and Discussion}

3.1. Temperature Measurement. The microtemperature sensor manufactured in this paper is a Pt resistance temperature detector (RTD). Due to the need for accurate temperature measurements, the purity of the Pt resistance is $99.9999 \%$. A water bath was used to heat the temperature sensor from $0^{\circ} \mathrm{C}$ to $50^{\circ} \mathrm{C}$ (the water temperature was monitored by a commercial temperature sensor (TES1310)), and a multimeter $(17 \mathrm{~B}+$, Fluke) was used to measure the resistance of the $\mathrm{Pt}$ RTD. The regression analysis results of the Pt RTD resistance Rt and temperature T are shown in Figure 7(a). The sensitivity is $0.949 \Omega /{ }^{\circ} \mathrm{C}$, and the linearity is 0.9994 , which shows that the Pt RTD can be used to detect temperature. The stability measurement of the temperature sensor was performed for 10 consecutive days, and the measurement results are shown in Figure 7(b). The stability test shows that the temperature is relatively stable, and even though the output fluctuates slightly, the change rate is less than $1 \%$.

3.2. DO Measurement. Regarding the measurements of the DO sensor, the three electrodes of the DO sensor (Figure 1) were connected to the electrodes at the corresponding positions of the potentiostat (Figure 6(b)). Sodium sulfite particles $\left(\mathrm{Na}_{2} \mathrm{SO}_{3}\right)$ were slowly dissolved in a $0.1 \mathrm{M} \mathrm{KCl}$ solution to prepare six solutions with different $\mathrm{DO}$ concentrations (1.5 mg/L, $3 \mathrm{mg} / \mathrm{L}, 4.5 \mathrm{mg} / \mathrm{L}, 6 \mathrm{mg} / \mathrm{L}, 7.5 \mathrm{mg} / \mathrm{L}$, and $9 \mathrm{mg} / \mathrm{L})$. Scanning was performed using cyclic voltammetry $(\mathrm{CV})$ at a scan rate of $0.1 \mathrm{~V} / \mathrm{s}$ and a scan range of $-1 \mathrm{~V}$ to $0 \mathrm{~V}$. The measurement results were calibrated by colorimetry.

The measurement principle of the DO sensor is to reduce the oxygen dissolved in the solution through an electrochemical reaction and measure the current generated by it. The chemical reaction on the electrode surface can be expressed as [20]:

$$
\mathrm{O}_{2}+2 \mathrm{H}_{2} \mathrm{O}+4 \mathrm{e}^{-} \longrightarrow 4 \mathrm{OH}^{-}
$$

The reaction on the working electrode surface of the DO sensor causes a change in current/potential. The CV model of the DO sensor is described below [22]:

$$
\frac{i}{i_{0}}=\left(1-\frac{i}{i_{1, c}}\right) e^{-\alpha n f \eta}-\left(1-\frac{i}{i_{1, a}}\right) e^{(1-\alpha) n f \eta},
$$

where $i_{0}$ is the alternating current, $n$ is the number of electrons, $\eta$ is the overpotential, $\alpha$ is the transfer coefficient, $f$ is the ratio of the Faraday constant to the ideal gas constant and temperature, and $i_{1, \mathrm{c}}$ and $i_{1, \mathrm{a}}$ are the diffusion-limited cathode current and anode current, respectively. Figure 8(a) shows the CV model of the sensor at different DO concentrations. The model describes two regions: a low-deviation kinetic control region (region 1) and a high-deviation diffusion control region (region 2 ). We used the current value at a potential of $0.8 \mathrm{~V}$ in region 2 as the concentration analysis current. Figure 8 (b) shows that the current is proportional to the DO concentration in region 2 . The sensitivity of the sensor is $2.22 \mu \mathrm{A} / \mathrm{ppm}$, and the linearity is also relatively high $\left(R^{2}=0.989\right)$. The stability test of the DO sensor was performed for 10 consecutive days. The measurement temperature was $25 \pm 2{ }^{\circ} \mathrm{C}$. The measurement results are shown in 


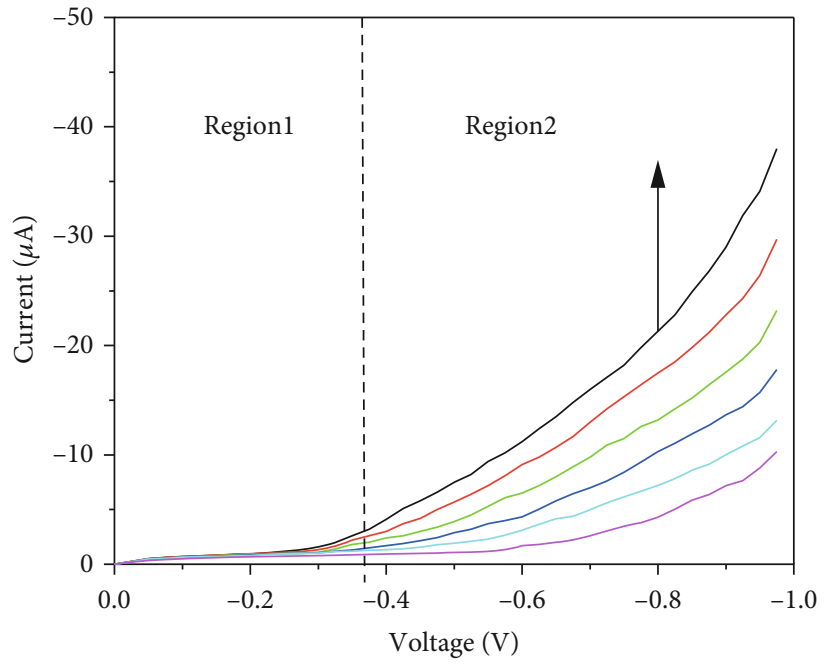

(a)

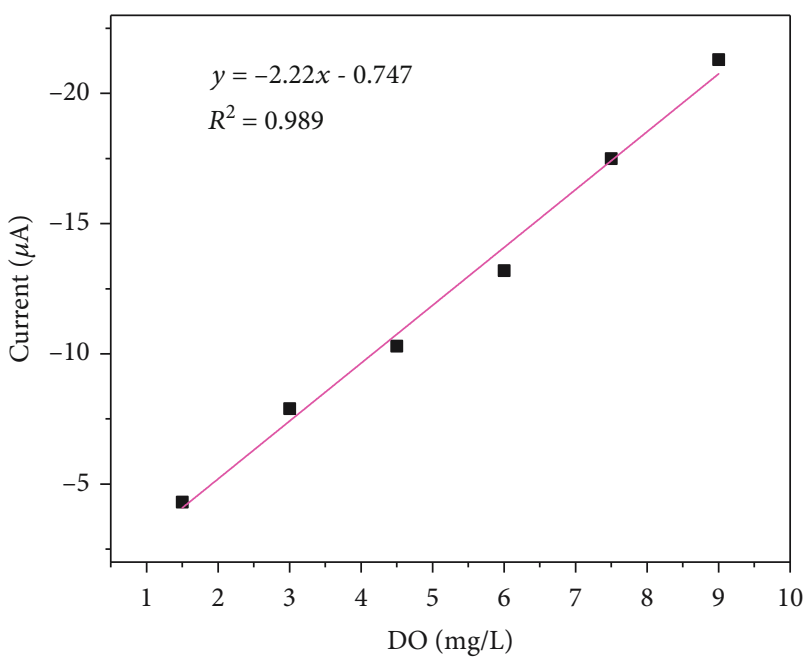

(b)

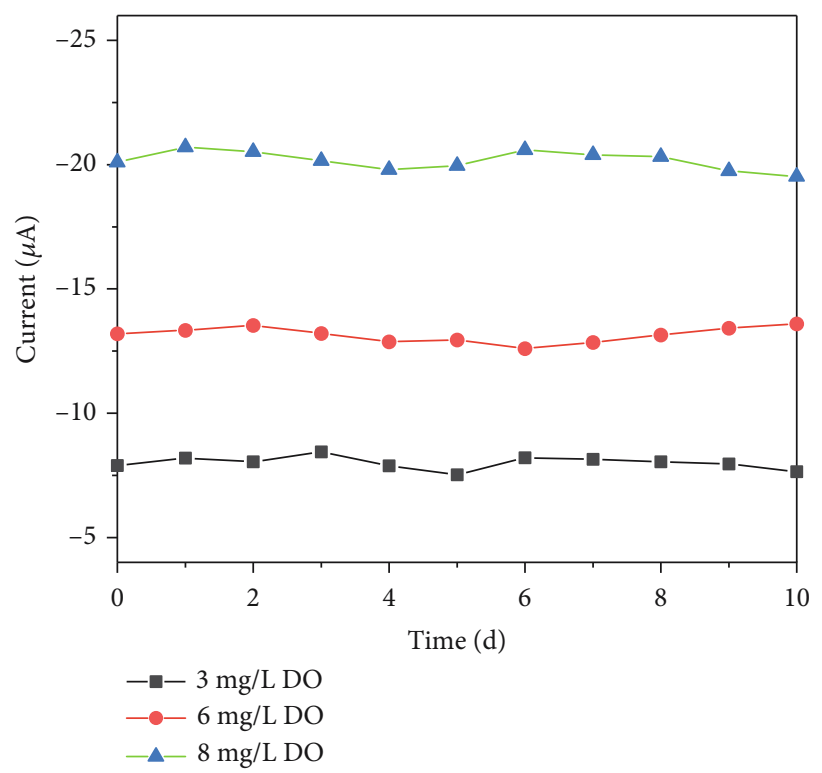

(c)

FIGURE 8: (a) CV mode of the sensor at different DO concentrations. (b) Fit curve of the sensor current to DO concentration. (c) Stability test results of the DO sensor over 10 consecutive days.

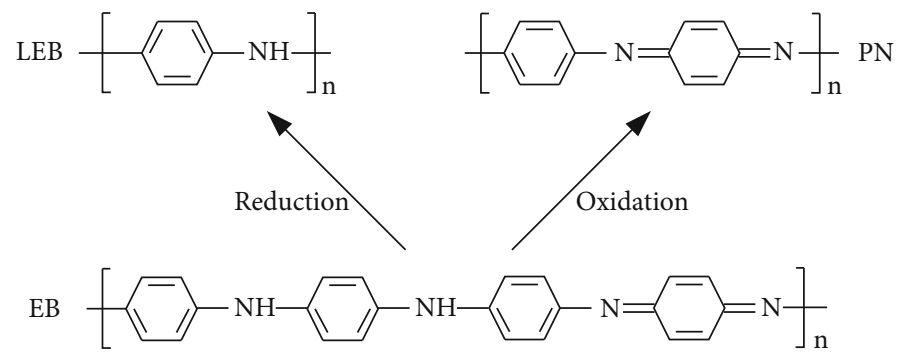

FIGURE 9: Generalized scheme of the polyaniline reaction.

Figure 8(c). The stability test shows that the DO concentration value is generally stable, and even though the output fluctuates slightly, the change rate is less than $4 \%$.
3.3. $\mathrm{pH}$ Measurement. For the $\mathrm{pH}$ sensor, the three electrodes of the $\mathrm{pH}$ sensor (Figure 1) were connected to the interface of the potentiostat (Figure 6(b)). Moreover, $0.1 \mathrm{M} \mathrm{H}_{3} \mathrm{PO}_{4}, 0.1 \mathrm{M}$ 


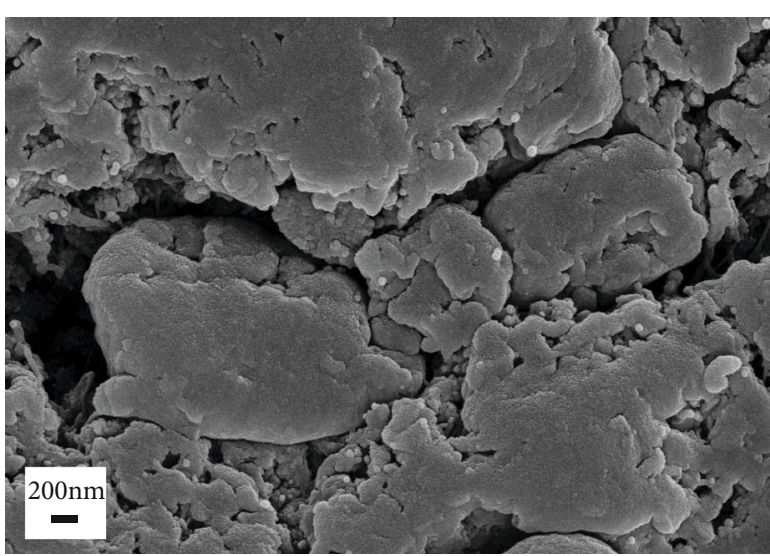

(a)

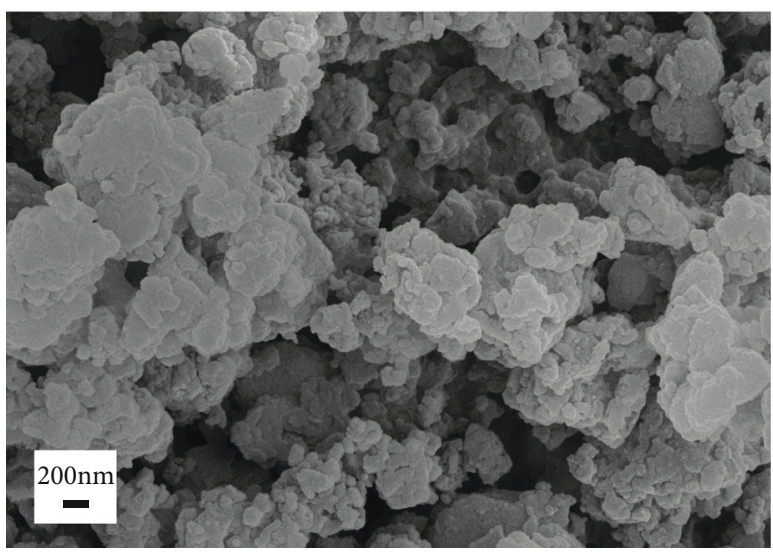

(c)

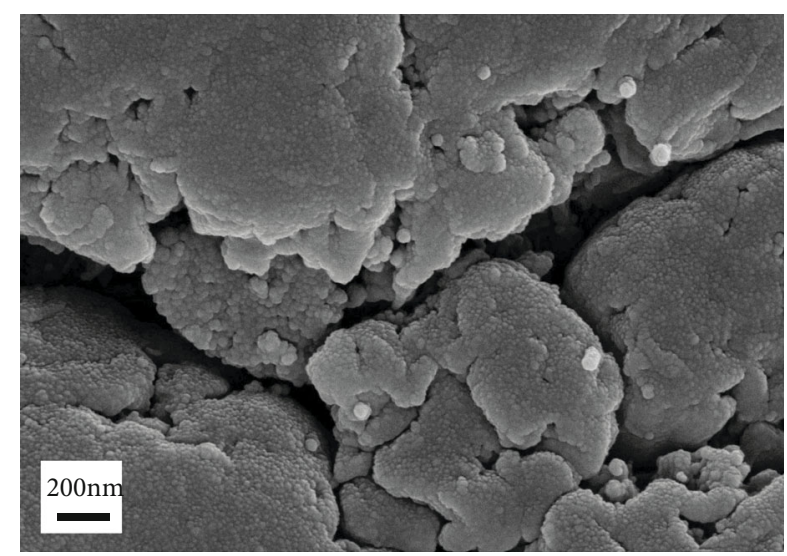

(b)

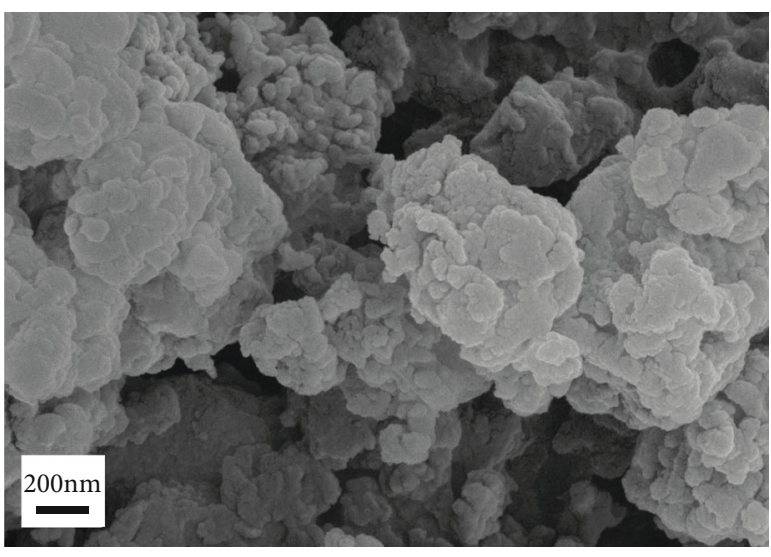

(d)

Figure 10: (a, b) SEM images of PANI. (c, d) SEM images of PANI/CuO.

$\mathrm{HOAc}$, and $0.1 \mathrm{M} \mathrm{NaOH}$ solutions were mixed to prepare $\mathrm{pH}$ ( $\mathrm{pH}=4,5,6,7,8$, and 9) buffer solutions. Additionally, a commercial $\mathrm{pH}$ meter (pHS-3E, Thunder Magnetic, China) was used to monitor the $\mathrm{pH}$ of the buffer solution. Each sample was measured at a positive potential of $1 \mathrm{~V}$ using the ampere method, the duration of the measurement was $5 \mathrm{~s}$, and the data acquisition system was used to monitor the variations in current.

The $\mathrm{pH}$ is detected by measuring the concentration of hydrogen ions. Among the PANI composites used in this study, the most common form of polyaniline is referred to as EB. Moreover, PANI is a remarkable $\mathrm{pH}$ sensing material. Under low $\mathrm{pH}$ conditions, there are more $\mathrm{H}^{+}$ions present in the solution, and the EB of PANI is converted into a pernigraniline base $(\mathrm{PN})$ via an oxidation process. When the $\mathrm{pH}$ is greater than 7 , there is an excess of $\mathrm{OH}^{-}$ions in the sample. When these ions approach the nanocomposite, EB is converted to LEB through a reduction reaction $[11,37]$, as shown in Figure 9. Considering that polyaniline and copper oxide composites have a better sensing effect on $\mathrm{pH}[32,33]$, this paper used PANI/CuO composites as the $\mathrm{pH}$-sensitive material.

The $\mathrm{pH}$ sensing mechanism of $\mathrm{CuO}$ can be described by the following redox reactions [32]:

$$
\begin{array}{r}
\mathrm{CuO}+2 \mathrm{H}^{+} \longrightarrow \mathrm{Cu}^{2+}+\mathrm{H}_{2} \mathrm{O} \\
\mathrm{Cu}^{2+}+2 \mathrm{OH}^{-} \longrightarrow \mathrm{CuO}+\mathrm{H}_{2} \mathrm{O}
\end{array}
$$

Scanning electron microscopy (SEM; Zeiss Supra 55) was used to analyze the morphology of the PANI and PANI/CuO composites. Figures 10(a) and 10(b) present the morphology of PANI, which reveals the porous structure of the macromolecular chain. Figures 10(c) and 10(d) present the morphology of the PANI/CuO composite. As seen from the figure, compared with those of PANI, the agglomeration effect of $\mathrm{PANI} / \mathrm{CuO}$ was more significant, and the interparticle gap was larger.

Figure 11(a) presents the current response of the $\mathrm{pH}$ sensor at different $\mathrm{pH}$ values. The measurement conditions were $25 \pm 2^{\circ} \mathrm{C}$. The fitted curve is shown in Figure 11(b), and the sensitivity of the sensor is $0.288 \mathrm{~mA} / \mathrm{pH}$. Based on the test results, the $\mathrm{pH}$ sensor demonstrates a high sensitivity and linearity $\left(R^{2}=0.9998\right)$. The stability test of the $\mathrm{pH}$ sensor was performed for 10 consecutive days, and the measurement conditions were $25 \pm 2^{\circ} \mathrm{C}$. The measurement results are shown in Figure 11(c). The stability test shows that the $\mathrm{pH}$ value is generally stable, and even though the output fluctuates slightly, the change rate is less than $6 \%$.

3.4. Ammonia Nitrogen Measurement. A total of $382.14 \mathrm{mg}$ of $\mathrm{NH}_{4} \mathrm{Cl}$ powder was dissolved in $1 \mathrm{~L}$ of water and configured as a $100 \mathrm{mg} / \mathrm{L}$ (calculated based on $\mathrm{N}$ content) ammonia nitrogen solution. A $0.1 \mathrm{M} \mathrm{KCl}$ solution was prepared as the supporting electrolyte. Different volumes of $\mathrm{NH}_{4} \mathrm{Cl}$ 


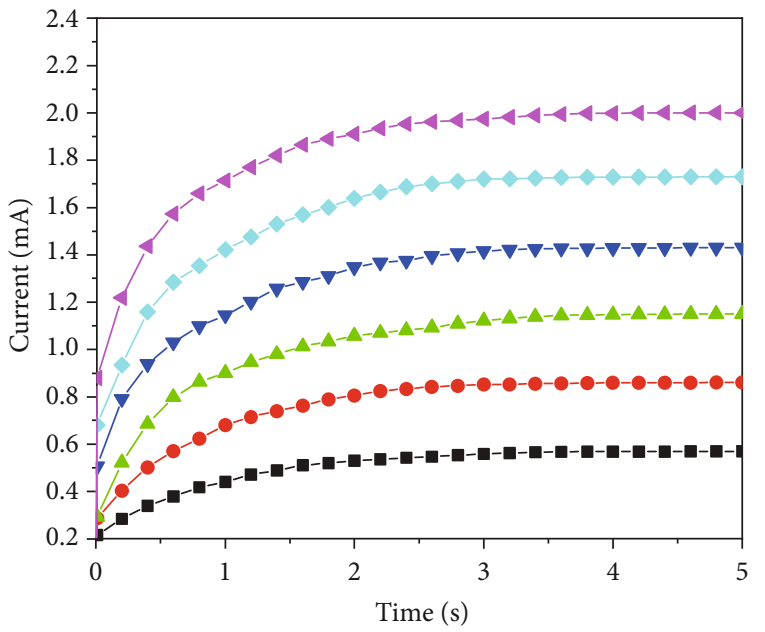

(a)

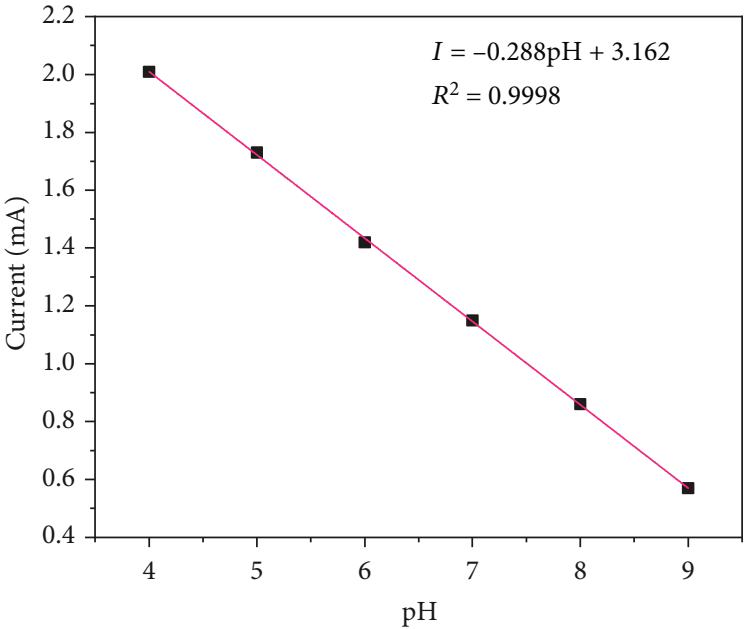

(b)

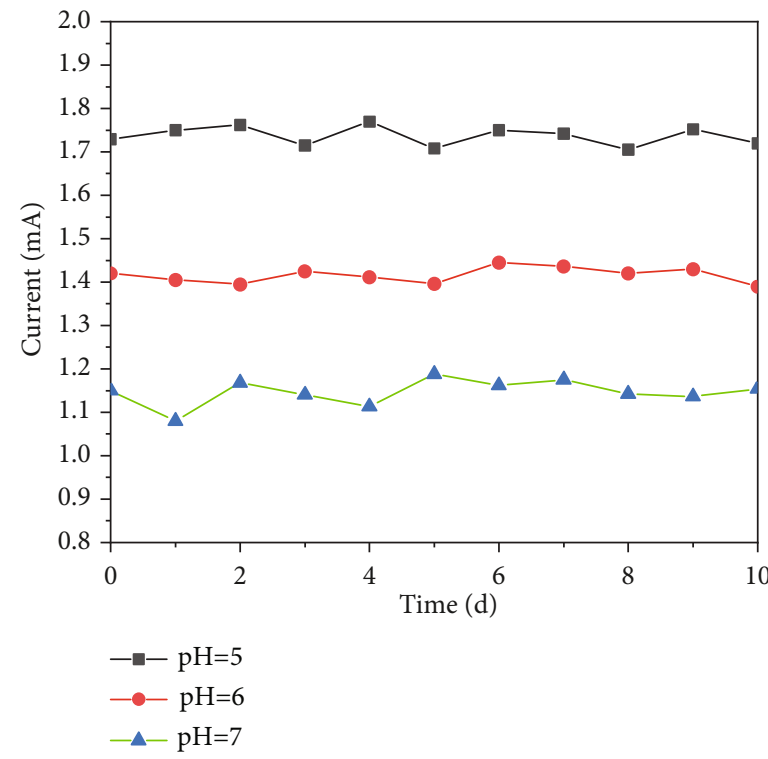

(c)

FIGURE 11: (a) Current response of the $\mathrm{pH}$ sensor for different $\mathrm{pH}$ values. (b) $\mathrm{pH}$ fitting curve. (c) Stability test results of the $\mathrm{pH}$ sensor over 10 consecutive days.

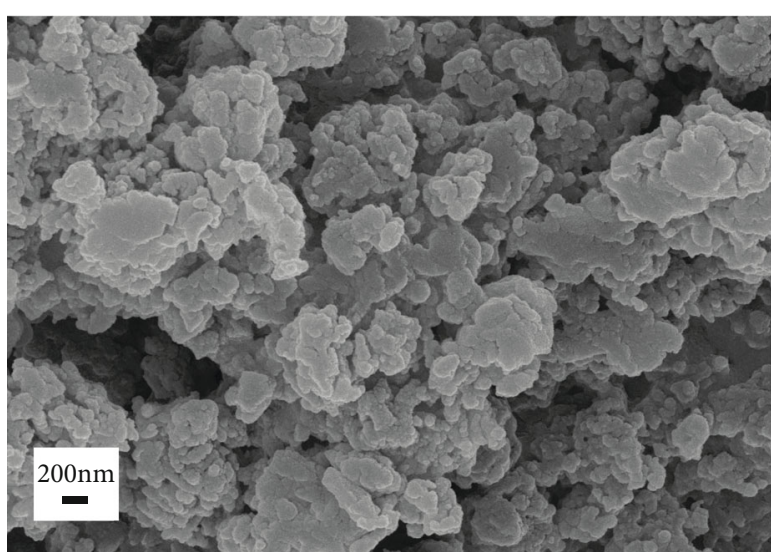

(a)

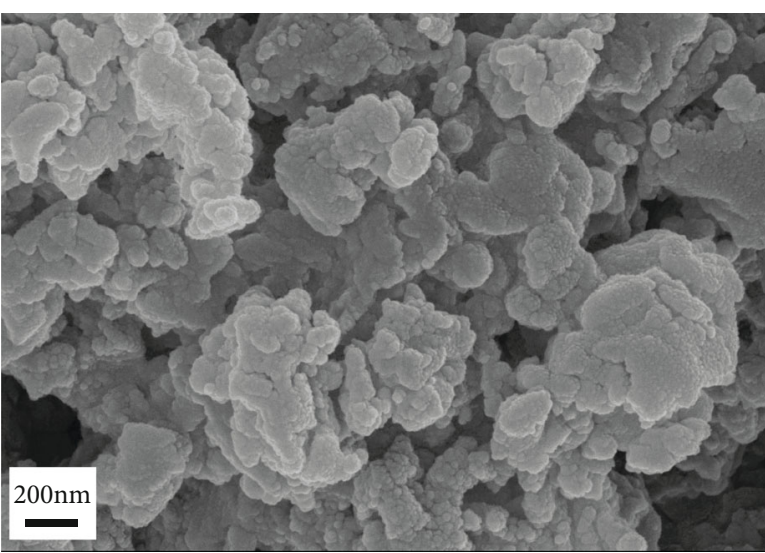

(b)

Figure 12: (a, b) SEM images of PANI/Cu. 


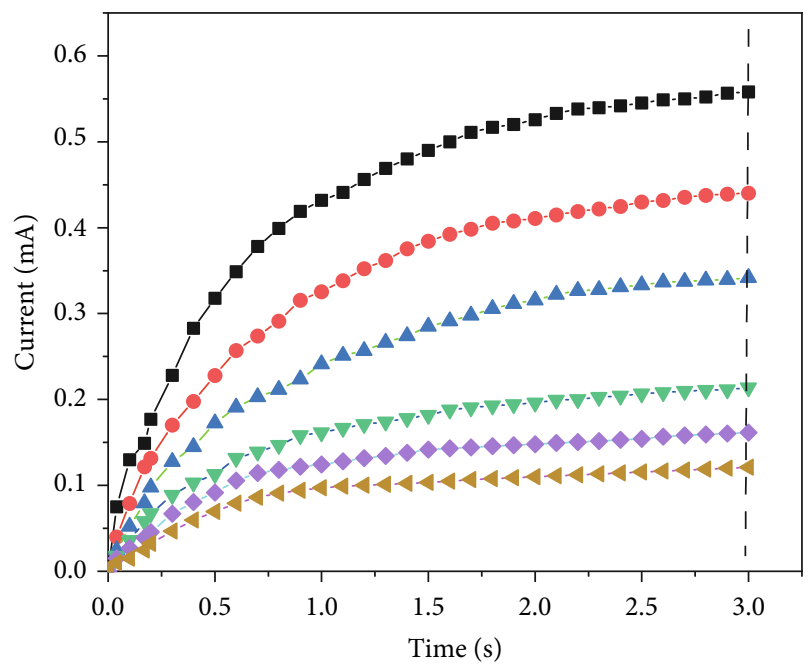

(a)

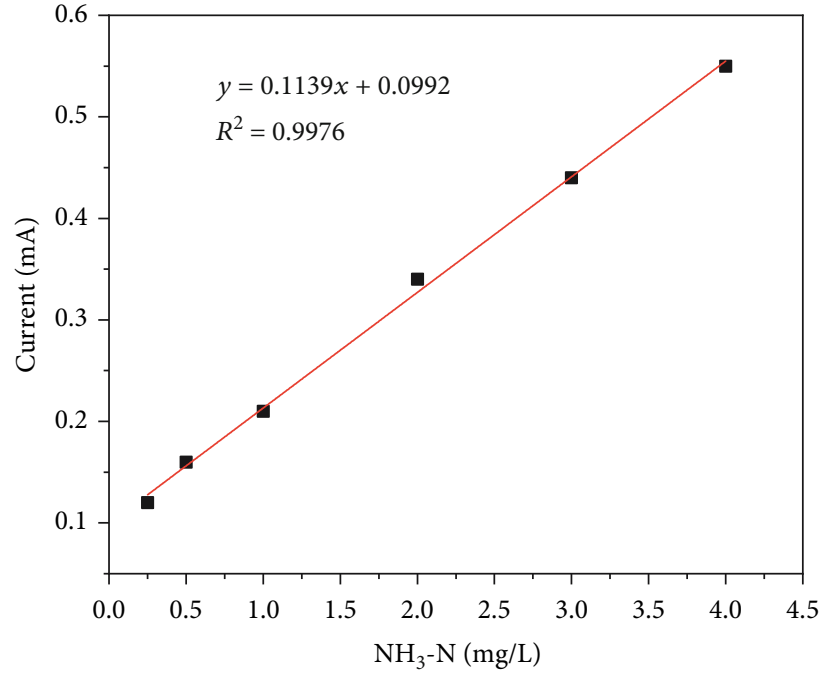

(b)

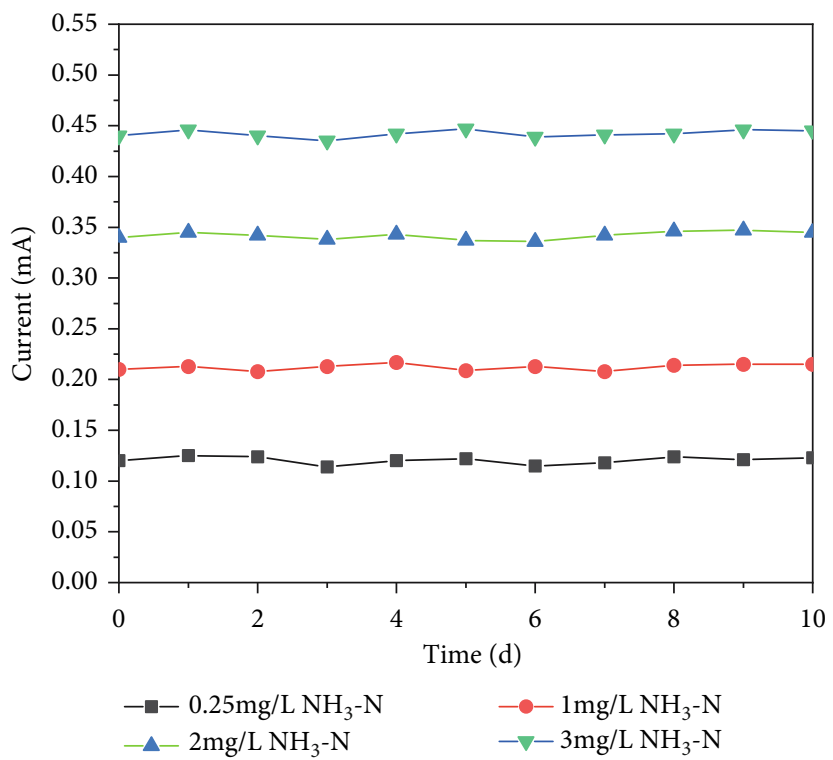

(c)

Figure 13: (a) Current response of the ammonia nitrogen sensor at different ammonia nitrogen concentrations. (b) Fitting curve of current and concentration. (c) Stability test results of the ammonia nitrogen sensor over 10 consecutive days.

solution were dissolved in the $\mathrm{KCl}$ solution and diluted to different concentrations $(4 \mathrm{mg} / \mathrm{L}, 3 \mathrm{mg} / \mathrm{L}, 2 \mathrm{mg} / \mathrm{L}, 1 \mathrm{mg} / \mathrm{L}$, $0.5 \mathrm{mg} / \mathrm{L}, 0.25 \mathrm{mg} / \mathrm{L}$ ) of ammonia nitrogen solution. The concentration of the solution was calibrated by the ammonia nitrogen standard color chart. During the test, the three electrodes of the ammonia nitrogen sensor (Figure 1) were connected to the corresponding positions of the potentiostat (Figure 6(b)). Each sample was measured at a positive potential of $1 \mathrm{~V}$ using the ampere method, the duration of the measurement was $3 \mathrm{~s}$, and the data acquisition system was used to monitor the variations in current.

Considering the excellent conductivity of PANI, it can be used for the detection of ammonia nitrogen $\left(\mathrm{NH}_{3}-\mathrm{N}\right)$ concentration, but undoped PANI has a low sensitivity to the concentration of $\mathrm{NH}_{3}-\mathrm{N}$ [38]. Nanocopper-doped PANI leads to significant changes in polymer properties. The SEM images of PANI/Cu are shown in Figures 12(a) and 12(b). Compared with that of the undoped PANI, the agglomeration effect of nanocopper-doped PANI is more obvious.

Furthermore, the ammonia nitrogen in the solution mainly exists in the form of ammonium ions $\left(\mathrm{NH}_{4}^{+}\right)$and free ammonia $\left(\mathrm{NH}_{3}\right)$. A modification of PANI/Cu on the electrode surface will lead to the formation of a complex between $\mathrm{Cu}^{2+}$ and free ammonia. This complex can be easily reduced to $\mathrm{Cu}^{+}$and subsequently oxidized to $\mathrm{Cu}^{2+}$ [39]. When the cathode current increases, it indicates that the formation of the ammonia complex promotes the occurrence of redox 
reactions. The redox reaction of the ammonia complex is as follows:

$$
\begin{gathered}
\mathrm{NH}_{4}^{+} \leftrightharpoons \mathrm{NH}_{3}+\mathrm{H}^{+} \\
\mathrm{Cu}^{0} \leftrightharpoons \mathrm{Cu}^{2+}+2 \mathrm{e}^{-} \\
\mathrm{Cu}^{2+}+2 \mathrm{NH}_{3} \leftrightharpoons \mathrm{Cu}\left(\mathrm{NH}_{3}\right)_{2}^{2+} \\
\mathrm{Cu}\left(\mathrm{NH}_{3}\right)_{2}^{2+}+e^{-} \leftrightharpoons \mathrm{Cu}\left(\mathrm{NH}_{3}\right)_{2}^{+}
\end{gathered}
$$

Figure 13(a) shows the current response of the ammonia nitrogen sensor at different concentrations. The measurement conditions were $25 \pm 2^{\circ} \mathrm{C}$. The fitted curve is shown in Figure 13(b), and the sensitivity of the sensor is $0.1139 \mathrm{~mA} / \mathrm{ppm}$. The test results show that the ammonia nitrogen sensor has high sensitivity and good linearity $\left(R^{2}=0.9976\right)$. The stability test of the ammonia nitrogen sensor was performed for 10 consecutive days. The measurement temperature was $25 \pm 2^{\circ} \mathrm{C}$, and the measurement results are shown in Figure 13(c). The stability test shows that the ammonia nitrogen concentration is relatively stable, and even though the output fluctuates slightly, the change rate is less than $5 \%$.

3.5. Temperature Compensation. A thermal analysis was conducted to investigate the heater using a thermal image analyzer (C3, FIIR). The initial sensor temperature $T_{0}$ was $22^{\circ} \mathrm{C}$ before heating. Different power levels were applied to the heater to obtain the temperature $T_{1}$ after heating. The temperature variation can be expressed as follows:

$$
\Delta T=T_{1}-T_{0}
$$

Table 1 summarizes the relationship between heating power and temperature. Figure 14 shows a linear relationship between the heating power and temperature variation.

From Figure 14, the linear relationship between the heating power and the temperature variation can be expressed as follows:

$$
\Delta T=0.3126 P-0.18
$$

According to the related literature [23-26], the $\mathrm{pH}$, ammonia nitrogen concentration, and DO concentration in an aqueous solution are affected by the solution temperature. Therefore, keeping the solution temperature constant (or within a small temperature range) is of great significance to improve the measurement accuracy. When the measured ambient temperature is low, the heater can be applied to reach $25-28^{\circ} \mathrm{C}$ according to the temperature value measured by the temperature sensor. When the solution temperature is high, external circulation of cold water can be applied to cool the entire sensor device. According to the temperature value monitored in real time, the measurement will be performed when the temperature is within $25-28^{\circ} \mathrm{C}$. Therefore, the influence of the solution temperature on the measurement accuracy is reduced.
TABLE 1: Relationship between temperature and heating power.

\begin{tabular}{lcc}
\hline Power $(\mathrm{mW})$ & $\begin{array}{c}\text { Temperature after } \\
\text { heating } T_{1}\left({ }^{\circ} \mathrm{C}\right)\end{array}$ & $\begin{array}{c}\text { Temperature variation } \\
\Delta T\left({ }^{\circ} \mathrm{C}\right)\end{array}$ \\
\hline 2.68 & 23.3 & 1.3 \\
6 & 24 & 2 \\
10.72 & 25.3 & 3.3 \\
16.76 & 27.6 & 5.6 \\
24.13 & 29.1 & 7.1 \\
32.84 & 31.3 & 9.3 \\
42.9 & 34.8 & 12.8 \\
54.29 & 38.5 & 16.5 \\
67.02 & 42.9 & 20.9 \\
81.1 & 46 & 24 \\
96.5 & 51.9 & 29.9 \\
113.3 & 58.4 & 36.4 \\
\hline
\end{tabular}

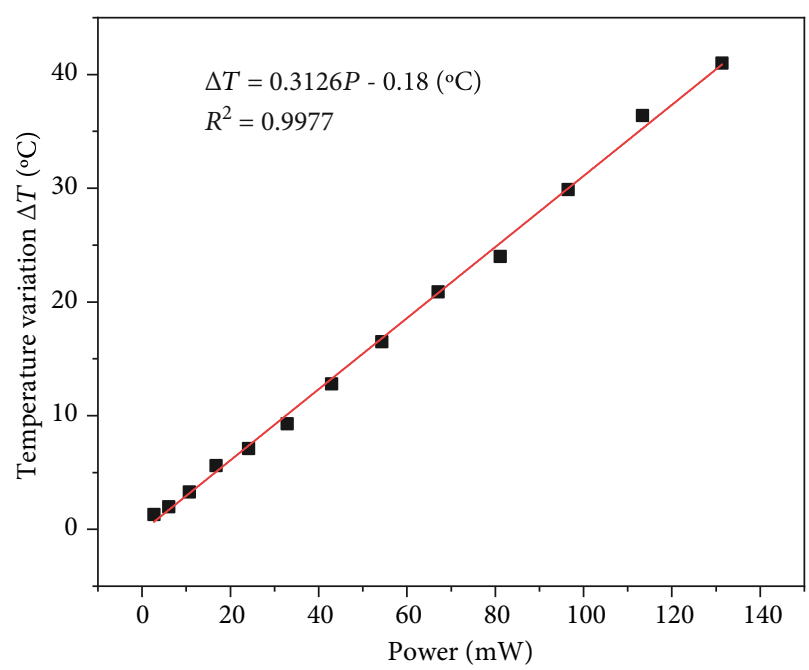

FIgURE 14: Relationship between the power and temperature variation.

Based on this feature, the sensor detection system is suitable for real-time measurement of remote waters.

3.6. Monitoring Real Water Samples. We used our developed multiparameter sensor to measure the parameters of tap water and Songhua River water. For $\mathrm{pH}$ detection, commercial glass electrodes (pHS-3E, Thunder magnetic, China) were used as a reference. For temperature detection, a commercial temperature sensor was used as a reference. Regarding the detection of the DO and ammonia nitrogen concentrations, a colorimetric test box was used as a reference. The values of the temperature, $\mathrm{pH}, \mathrm{DO}$ concentration, and ammonia nitrogen concentration from the multifunctional sensor were compared with the results from the reference methods, and the results are shown in Table 2. From Table 2, the results measured by our system are close to those measured by the reference method. 
TABLE 2: Comparison of results for the four measured parameters.

\begin{tabular}{lcccc}
\hline & \multicolumn{2}{c}{ Tap water } & \multicolumn{2}{c}{ Songhua River water } \\
& Multiparameter sensor & Reference & Multiparameter sensor & Reference \\
\hline $\mathrm{pH}$ & $6.92 \pm 0.1$ & $6.95 \pm 0.08$ & $7.65 \pm 0.23$ & $7.68 \pm 0.1$ \\
$\mathrm{DO}(\mathrm{mg} / \mathrm{L})$ & $8.65 \pm 0.31$ & $8.75 \pm 0.11$ & $6.62 \pm 0.35$ & $6.73 \pm 0.12$ \\
$\mathrm{NH}_{3}-\mathrm{N}(\mathrm{mg} / \mathrm{L})$ & $0.34 \pm 0.08$ & $0.36 \pm 0.02$ & $1.78 \pm 0.07$ & $1.84 \pm 0.02$ \\
Temperature $\left({ }^{\circ} \mathrm{C}\right)$ & $15.26 \pm 0.51$ & $15.13 \pm 0.11$ & $20.18 \pm 0.54$ & $20.06 \pm 0.1$ \\
\hline
\end{tabular}

\section{Conclusions}

We proposed an integrated multiparameter sensor chip for monitoring the following four parameters of water samples: temperature, $\mathrm{pH}$, DO concentration, and ammonia nitrogen concentration. To achieve temperature compensation, a serpentine heater was designed on the chip to ensure the ideal temperature for sensor measurements. The sensor chip size was approximately $2 \mathrm{~cm} \times 2 \mathrm{~cm}$. The sensitivity of the temperature sensor was $0.949 \Omega /{ }^{\circ} \mathrm{C}$, and the sensitivity of the DO sensor was $2.22 \mu \mathrm{A} / \mathrm{ppm}$. Additionally, PANI/CuO was modified on the electrode surface as a $\mathrm{pH}$-sensitive material, and the sensor showed a good sensitivity of $0.288 \mathrm{~mA} / \mathrm{pH}$. $\mathrm{PANI} / \mathrm{Cu}$ was modified on the electrode as an ammonia nitrogen-sensitive material and showed a good sensitivity of $0.1139 \mathrm{~mA} / \mathrm{ppm}$. The power and temperature sensitivity of the heater was $0.3126^{\circ} \mathrm{C} / \mathrm{mW}$. The advantages of this sensor chip and detection system are as follows:

(i) The following four parameters of a solution can be measured simultaneously: temperature, $\mathrm{pH}, \mathrm{DO}$ concentration, and ammonia nitrogen concentration

(ii) $\mathrm{PANI} / \mathrm{Cu}$ as a sensitive material for ammonia nitrogen and $\mathrm{PANI} / \mathrm{CuO}$ as a $\mathrm{pH}$-sensitive material both show good sensitivity

(iii) The sensor integrated multiple identical threeelectrode arrays, which can be used as a chip laboratory to compare and measure a single parameter and find the best measurement solution

(iv) The sensor array can be modified by different sensitive membranes, which allows it to measure other water quality parameters such as nitrate, heavy metal ions, and chloride ions

(v) The sensor has a heating element, which can heat the solution to be measured to an ideal measurement temperature, thus improving measurement accuracy

(vi) The sensor detection system is small in size, economical, structurally stable, and durable. Moreover, a microperistaltic pump with a control valve can realize automatic control of the detection system

In this paper, the corresponding electrodes were modified by using an adhesive coating method. This method may cause the thickness of the modified sensitive film to be slightly different, which will slightly affect the measurement results. Therefore, the next research direction will use other methods to modify the electrode to ensure that the thickness of the modified sensitive film is consistent. In summary, the multiparameter sensor chip studied in this paper was suitable for drinking water detection. The sensor chip was small and rugged and suitable for portable or online water quality detection systems.

\section{Data Availability}

The data used to support the findings of this study are available from the corresponding author upon request.

\section{Conflicts of Interest}

The authors declare that there is no conflict of interest regarding the publication of this paper.

\section{Acknowledgments}

This study has been supported by a Project of Defense Industrial Technology Development Program No. JCKY2017412C003.

\section{References}

[1] B. Zhou, C. Bian, J. Tong, and S. Xia, "Fabrication of a miniature multi-parameter sensor chip for water quality assessment," Sensors, vol. 17, no. 12, p. 157, 2017.

[2] R. P. Buck, S. Rondinini, A. K. Covington et al., "Measurement of $\mathrm{pH}$. Definition, standards, and procedures (Iupac Recommendations 2002)," Pure and Applied Chemistry, vol. 74, no. 11, pp. 2169-2200, 2002.

[3] J. A. Cotruvo, "2017 WHO guidelines for drinking water quality: first addendum to the fourth edition," Journal - American Water Works Association, vol. 109, no. 7, pp. 44-51, 2017.

[4] Y. Qin, H.-J. Kwon, M. M. R. Howlader, and M. J. Deen, "Microfabricated electrochemical $\mathrm{pH}$ and free chlorine sensors for water quality monitoring: recent advances and research challenges," RSC Advances, vol. 5, no. 85, pp. 69086-69109, 2015.

[5] Y. Zheng, L. H. Chen, X. Dong et al., "Miniature pH optical fiber sensor based on Fabry-Perot interferometer," IEEE Journal of Selected Topics in Quantum Electronics, vol. 22, no. 2, pp. 331-335, 2016.

[6] C. T. Lee, Y. S. Chiu, L. R. Lou, S. C. Ho, and C. T. Chuang, "Integrated $\mathrm{pH}$ sensors and performance improvement mechanism of ZnO-based ion-sensitive field-effect transistors," IEEE Sensors Journal, vol. 14, no. 2, pp. 490-496, 2014. 
[7] N. Bahari, A. M. Zain, A. Z. Abdullah, D. B. C. Sheng, and M. Othman, "Study on $\mathrm{pH}$ sensing properties of RF magnetron sputtered tantalum pentoxide $\left(\mathrm{Ta}_{2} \mathrm{O}_{5}\right)$ thin film," in 2010 IEEE International Conference on Semiconductor Electronics (ICSE2010), Melaka, Malaysia, June 2010.

[8] W.-D. Zhang and B. Xu, "A solid-state $\mathrm{pH}$ sensor based on $\mathrm{WO}_{3}$-modified vertically aligned multiwalled carbon nanotubes," Electrochemistry Communications, vol. 11, no. 5, pp. 1038-1041, 2009.

[9] K. A. Yusof, R. Abdul Rahman, M. A. H. Zulkefle, S. H. Herman, and W. F. H. Abdullah, "EGFET pH sensor performance dependence on sputtered $\mathrm{TiO}_{2}$ sensing membrane deposition temperature," Journal of Sensors, vol. 2016, Article ID 7594531, 9 pages, 2016.

[10] L. Manjakkal, B. Sakthivel, N. Gopalakrishnan, and R. Dahiya, "Printed flexible electrochemical pH sensors based on $\mathrm{CuO}$ nanorods," Sensors and Actuators B: Chemical, vol. 263, pp. 50-58, 2018.

[11] Z. Jin, Y. Su, and Y. Duan, "An improved optical pH sensor based on polyaniline," Sensors \& Actuators B, vol. 71, no. 1-2, pp. 118-122, 2000.

[12] A. Alitalo, A. Kyrö, and E. Aura, "Ammonia stripping of biologically treated liquid manure," Journal of Environmental Quality, vol. 41, no. 1, pp. 273-280, 2012.

[13] T. Manios, E. I. Stentiford, and P. A. Millner, "The removal of Indicator Microorganisms from primary treated wastewater in subsurface reed beds using different substrates," Environmental Letters, vol. 23, no. 7, pp. 767-774, 2002.

[14] J. Ho Shin, S. Yong Yoon, I. Jun Yoon et al., "Potentiometric biosensors using immobilized enzyme layers mixed with hydrophilic polyurethane," Sensors and Actuators B: Chemical, vol. 50, no. 1, pp. 19-26, 1998.

[15] W. J. Cho and H.-J. Huang, “An amperometric urea biosensor based on a polyaniline-perfluorosulfonated ionomer composite electrode," Analytical Chemistry, vol. 70, no. 18, pp. 39463951, 1998.

[16] M. Thompson, U. J. Krull, and L. I. Bendell-Young, "The bilayer lipid membrane as a basis for a selective sensor for ammonia," Talanta, vol. 30, no. 12, pp. 919-924, 1983.

[17] H. Tai, Y. Yang, S. Liu, and D. Li, “A review of measurement methods of dissolved oxygen in water," in Computer and Computing Technologies in Agriculture V. CCTA 2011. IFIP Advances in Information and Communication Technology, vol 369, D. Li and Y. Chen, Eds., Springer, Berlin, Heidelberg, 2012.

[18] I. Helm, L. Jalukse, M. Vilbaste, and I. Leito, "Micro-winkler titration method for dissolved oxygen concentration measurement," Analytica Chimica Acta, vol. 648, no. 2, pp. 167-173, 2009.

[19] P. Sahoo, R. Ananthanarayanan, N. Malathi, M. P. Rajiniganth, N. Murali, and P. Swaminathan, "Pulsating potentiometric titration technique for assay of dissolved oxygen in water at trace level," Analytica Chimica Acta, vol. 669, no. 1-2, pp. 17-24, 2010.

[20] J. H. Lee, T. S. Lim, Y. Seo, P. L. Bishop, and I. Papautsky, "Needle-type dissolved oxygen microelectrode array sensors for in situ measurements," Sensors and Actuators B-Chemical, vol. 128, no. 1, pp. 179-185, 2007.

[21] S. Zhuiykov, "Potentiometric DO detection in water by ceramic sensor based on sub-micron $\mathrm{RuO}_{2}$ sensing electrode," Ionics, vol. 15, no. 6, pp. 693-701, 2009.
[22] G. W. Mclaughlin, K. Braden, B. Franc, and G. T. A. Kovacs, "Microfabricated solid-state dissolved oxygen sensor," Sensors and Actuators B: Chemical, vol. 83, no. 1-3, pp. 138-148, 2002.

[23] J. J. Barron, C. Ashton, and L. Geary, "The effects of temperature on pH measurement," in Dept. Tech. Services Reagecon Diagnostics Ltd,Southampton State Univ, vol. TSP-01, Shannon Free Zone, Dubhlinn, Ireland, Rep, 2005.

[24] S. Bhadra, D. S. Y. Tan, D. J. Thomson, M. S. Freund, and G. E. Bridges, "A wireless passive sensor for temperature compensated remote $\mathrm{pH}$ monitoring," IEEE Sensors Journal, vol. 13, no. 6, pp. 2428-2436, 2013.

[25] H. Li, A. Shi, M. Li, and X. Zhang, "Effect of pH, temperature, dissolved oxygen, and flow rate of overlying water on heavy metals release from storm sewer sediments," Journal of Chemistry, vol. 2013, 11 pages, 2013.

[26] Y. Wen, Y. Mao, Z. Kang, and Q. Luo, "Application of an ammonium ion-selective electrode for the real-time measurement of ammonia nitrogen based on $\mathrm{pH}$ and temperature compensation," Measurement, vol. 137, pp. 98-101, 2019.

[27] C. Y. Lee, S. J. Lee, M. S. Tang, and P. C. Chen, "In situ monitoring of temperature inside lithium-ion batteries by flexible micro temperature sensors," Sensors, vol. 11, no. 10, pp. 9942-9950, 2011.

[28] M. Sezen, J. T. Register, Y. Yao, B. Glisic, and Y.-L. Loo, “Eliminating piezoresistivity in flexible conducting polymers for accurate temperature sensing under dynamic mechanical deformations," Small, vol. 12, no. 21, pp. 2832-2838, 2016.

[29] H. Suzuki, T. Hirakawa, S. Sasaki, and I. Karube, "An integrated three-electrode system with a micromachined liquidjunction $\mathrm{Ag} / \mathrm{AgCl}$ reference electrode," Analytica Chimica Acta, vol. 387, no. 1, pp. 103-112, 1999.

[30] Z. Xu, Q. Dong, B. Otieno et al., "Real-time in situ sensing of multiple water quality related parameters using microelectrode array (MEA) fabricated by inkjet-printing technology (IPT)," Sensors and Actuators B-Chemical, vol. 237, pp. 1108-1119, 2016.

[31] H. Essousi, H. Barhoumi, M. Bibani et al., "Ion-imprinted electrochemical sensor based on copper nanoparticles-polyaniline matrix for nitrate detection," Journal of Sensors, vol. 2019, Article ID 4257125, 14 pages, 2019.

[32] M. B. Gholivand, H. Heydari, A. Abdolmaleki, and H. Hosseini, "Nanostructured $\mathrm{CuO} / \mathrm{PANI}$ composite as supercapacitor electrode material," Materials Science in Semiconductor Processing, vol. 30, pp. 157-161, 2015.

[33] A. Sedighi, M. Montazer, and S. Mazinani, "Synthesis of wearable and flexible NiP0.1-SnOx/PANI/CuO/cotton towards a non-enzymatic glucose sensor," Biosensors and Bioelectronics, vol. 135, pp. 192-199, 2019.

[34] Y. Luo, Y. Kun, Y. Shi, and C. Shang, "Research of radiosonde humidity sensor with temperature compensation function and experimental verification," Sensors and Actuators A: Physical, vol. 218, pp. 49-59, 2014.

[35] X. Wang, L. Sun, T. Wang, and Y. Shi, "Temperature-compensated $\mathrm{pH}$ microelectrode array sensors based on copper-oxide/polyaniline modification," IEEE Sensors Journal, p. 1, 2020.

[36] A. S. Selvanayagam, J. B. Gopalakrishnan, and J. B. B. Rayappan, "Preparation, characterization and chemical sensing properties of polyaniline thin films," Journal of Applied Sciences, vol. 12, no. 16, pp. 1710-1713, 2012.

[37] V. Semwal and B. D. Gupta, "Highly sensitive surface plasmon resonance based fiber optic $\mathrm{pH}$ sensor utilizing RGO-Pani 
nanocomposite prepared by in situ method," Sensors and Actuators B: Chemical, vol. 283, pp. 632-642, 2019.

[38] M. T. Zhybak, M. Y. Vagin, V. Beni et al., "Direct detection of ammonium ion by means of oxygen electrocatalysis at a copper-polyaniline composite on a screen-printed electrode," Microchimica Acta, vol. 183, no. 6, pp. 1981-1987, 2016.

[39] I. Giannopoulou, D. Panias, and I. Paspaliaris, "Electrochemical modeling and study of copper deposition from concentrated ammoniacal sulfate solutions," Hydrometallurgy, vol. 99, no. 1-2, pp. 58-66, 2009. 